\title{
Discussion and Reflection of Formative Evaluation Integrated into the Classroom Teaching Mode of PAD Class in the "Internet Plus" Era
}

\author{
Yan Li, Suoyi Huang, Xiufeng Huang, Yan-e Zhou, Qianli Tang*, Xianjiu Liao* \\ Youjiang Medical University for Nationalities, Baise, China \\ Email: ^htmgx919@163.com, *lxj2006910@163.com
}

How to cite this paper: Li, Y., Huang, S. Y., Huang, X. F., Zhou, Y.-E, Tang, Q. L., \& Liao, X. J. (2020). Discussion and Reflection of Formative Evaluation Integrated into the Classroom Teaching Mode of PAD Class in the "Internet Plus" Era. Creative Education, 11, 1521-1527.

https://doi.org/10.4236/ce.2020.118110

Received: August 13, 2020

Accepted: August 25, 2020

Published: August 28, 2020

Copyright $\odot 2020$ by author(s) and Scientific Research Publishing Inc. This work is licensed under the Creative Commons Attribution International License (CC BY 4.0).

http://creativecommons.org/licenses/by/4.0/

\begin{abstract}
In the "Internet plus Education" era, the traditional summative evaluation has been difficult to evaluate some learning elements objectively and scientifically when teaching online, with the rise of network teaching, especially mobile information based teaching, and under the PAD classroom teaching mode dominated by students and instructed by teachers. PAD class provides an idea to solve the problem of teaching quality decline in current college classroom, rather than to handle a certain subject. So far, less attention has been paid to PAD classroom teaching evaluation. This paper discusses the adaptability of formative evaluation when being integrated into PAD class, discusses the evaluation system of the formative evaluation when being integrated into PAD class mode, and reflects on the formative evaluation when being integrated into PAD class.
\end{abstract}

\section{Keywords}

PAD Classes, Formative Evaluation, Teaching Reform, Medical College, "Internet Plus"

\section{Introduction}

PAD class is a novel classroom teaching mode proposed in 2014. While affirming the teachers' instruction, PAD class emphasizes that half of the classroom hours shall be reserved for students, and the students shall be transformed from passive learning to active learning, so that students can find problems, discuss problems, solve problems, and display their learning achievements (Zhao \& ${ }^{*}$ Corresponding authors. 
Zhang, 2018). To make the students have enough time to prepare the presentation of knowledge achievements, PAD class divides the teaching into three parts: presentation, assimilation and discussion. It emphasizes that teachers' presentation and students' discussion \& performance shall be staggered in time. The staggered time is exactly the period for students to explore and assimilate knowledge independently, which is aimed to fully mobilize students' initiatives and participation in learning, and to improve students' knowledge application ability.

In the context of "Internet plus Education", the traditional summative evaluation has been difficult to evaluate some learning elements objectively and scientifically when teaching online, with the rise of network teaching, especially mobile information based teaching, and under the PAD classroom teaching mode dominated by students and instructed by teachers, for example, the students' interest in and attitude to learning, ability in independent learning, ability to participate in teamwork learning and other learning elements. Formative evaluation focuses on students' learning as a process where teachers collect relevant information while teaching to understand students' learning status and adjust teaching activities; students make up for the defects in learning according to the information provided by the formative evaluation. The main objective beneath formative evaluation is to improve teaching and learning (Wang, Gong, $\mathrm{Zhu}$, Yang, Gao, He, Lin, \& Bu, 2020). Therefore, we discussed the formative evaluation integrated into the PAD classroom teaching mode in the "Internet plus" era.

\section{Status Quo of Teaching Evaluation in Medical Colleges in Minority Areas}

The discipline of medicine requires lifelong learning, however, the knowledge presented in the classroom is limited, and thus more knowledge shall be learned independently by students while the medical practice in the future, for which it is of crucial importance to cultivate students' self-learning ability (Sun, Hu, Chen, $\mathrm{Hu}, \& \mathrm{Li}, 2020)$. Traditional medical course assessments are based on summative evaluation, which mainly focus on the textbooks and pays attention to fragmented knowledge to be memorized. Students tend to have low interest in learning, stress theory than practice, and cannot use knowledge to analyze and solve problems, whose independent learning and lifelong learning are impossible.

The Chinese Undergraduate Medical Education Standard-Clinical Medicine (2016) formulated by the Working Committee for the Accreditation of Medical Education, MOE, points out that "while managing the summative evaluation, we shall apply more formative evaluations and give feedback in time, to guide students to learn better". Although the Ministry of Education has repeatedly called for the introduction of formative evaluation in the medical education, a higher proportion of formative evaluation, and the combination of formative evaluation and summative evaluation to promote the medical education level, the formative evaluation is still a peripheral mode among all the teaching modes of medical 
colleges in minority areas, such as Youjiang Medical University for Nationalities, which is not emphasized adequately and accounts for a small proportion in the total scores. As a result, summative evaluation often plays a decisive role, which hinders the promoting effect of formative evaluation on teaching.

\section{Adaptability of Formative Evaluation Integrated into PAD Class}

First of all, one of the core concepts in PAD class is to highlight the dominant position of students in learning and facilitate their independent learning. Compared with the traditional evaluations, formative evaluation highlights the dominant position of students in learning, and stresses that the evaluation subject is students, which coincides with the teaching concept in PAD class. Secondly, PAD class highlights the coordinated development of students' emotional attitude, teamwork and self-learning ability. Formative evaluation also focuses on students' growth as a process, and stresses the cultivation of students' knowledge, skills, emotional attitude, teamwork, etc. Finally, the evaluation content in PAD class is more abundant than that of the traditional classroom, so the evaluation measures shall be taken from multiple perspectives. Different evaluation measures, such as the combination of quantitative evaluation and non-quantitative evaluation, shall be taken before and during class.

\section{Discussion on Formative Evaluation Integrated into PAD Class}

PAD class was introduced as a new teaching mode because the traditional teaching and evaluation modes had been inapplicable, and the evaluation reform was imperative. Formative evaluation is the inherently required by the teaching mode of PAD class. The application of self-learning ability through the whole PAD classroom teaching mode and construction of a reasonable, objective, comprehensive and humanized evaluation mode of multiple stages, levels and perspectives can stimulate students' learning enthusiasm, improve their self-learning ability, and further improve the quality of medical education (Sun, 2018).

1) Evaluation of In-class Presentation

PAD class mainly consists of presentation, assimilation and discussion. While presentation, the teachers sort out the knowledge framework, key teaching points and difficulties in corresponding units systematically, and assign clear after-school learning tasks for students, so that students can learn the specific knowledge content independently, find problems, query literatures and find the answers. Students will assimilate the knowledge better by independently exploring and applying knowledge than by the after-class consolidation and review of traditional teaching. We can adopt Duifene Teaching Platform in this step to record the students' such class performance as attendance and classroom questioning, and then conduct formative evaluation according to the statistical data provided by the platform.

2) Evaluation of Extracurricular Independent Learning 
Since the assimilation is conducted between presentation and discussion, students have enough time to complete their assignments, carry out personalized assimilation, and produce learning achievements for classroom discussion. Teachers guide and control the assimilation by assigning learning tasks. Therefore, students' independent learning results after class shall be displayed in different ways, such as "Liang Kao Bang" to present the learning contents they have mastered. The assimilation can assist students in examining and reflecting on their own learning, thus the evaluation at this stage can be carried out based on the teacher's evaluation and students' self-evaluation. Teachers can evaluate on the students' independent learning correspondingly, and display and comment on the good assignments completed. Students' self-evaluation is an elementary step in the practice and organization of formative evaluation. Teachers shall guide students to find their own uniqueness while self-evaluation and enhance their confidence in independent learning. We can adopt Duifene Teaching Platform in this step to score and record such independent learning performance as online assignments, watching video resources and online discussion, and then conduct formative evaluation according to the statistical data provided on the platform.

3) Evaluation of Group Discussion during Course

The discussion in PAD class consists of group discussion, inter-group discussion and class presentation. All the students in the classroom are grouped into several groups as per the random grouping of Duifene Teaching Platform. The group discussion and inter-group discussion involves "Liang Kao Bang" assignments assimilated, whose objective is to explore the problems encountered while independent learning. Classroom presentation is aimed to provide students with the opportunity to apply knowledge, allow them to present the achievements of knowledge assimilation after class, and recognize their efforts. Classroom evaluation scores mainly based on teamwork, problem-solving ability and personal contribution. Formative evaluation of classroom discussion can effectively stimulate students' participation in classroom discussion and activate the classroom atmosphere. We can adopt Duifene Teaching Platform in this step to record the students' such class performance as online attendance and online classroom discussion, and then conduct formative evaluation according to the statistical data provided by the platform.

\section{Reflection on Formative Evaluation Integrated into PAD Classroom Teaching Mode}

Facing the general trend of formative evaluation, teachers of the medical colleges in minority areas are laggard in the concept of how to implement formative evaluation. Corresponding theory and method training of formative evaluation based education has not been effectively carried out among the teaching staff of the medical colleges in minority areas. The construction and implementation of formative evaluation system is a new concept for teachers and students, most of the students not quite adapted to such mode and most of the teachers lacking 
relevant knowledge and awareness, who tend to shrink back from difficulties, thus returning to the summative evaluation eventually (Wu, Lin, \& Zhou, 2019). Therefore, first of all, we shall change the old-fashioned concepts, update the teaching concept, change the status quo of teacher-dominated classroom, and encourage teachers to participate in teaching reform.

In the current context where the medical colleges are large in scale and massive in enrollment, the theory teaching is mainly done in large classes. Since formative evaluation increases the teachers' workload, it is difficult to carry out in large classes (Wang, Huang, Wu, Luo, Chen, Li, Huang, Li, Zhao, Fang, \& Li, 2019). Especially for some clinical teachers in medical colleges, in addition to clinical care, they engage in teaching, thus bearing tremendous workload. Therefore, the reform in teaching mode and evaluation mode puts forward higher requirements for the number and quality of teachers, especially for teachers who engage in clinical care simultaneously and need to spend more time and energy.

In addition, the formative evaluation adopted by some teachers involves students' attendance, classroom questioning, assignment, classroom tests and other contents, and all the items are scored and recorded in proportion to complete the evaluation. Such method and thought are incomplete. Formative evaluation focuses on the feedback of students' learning effect and learning status. If the above items are scored simply, they will turn formative evaluation into a staged summative evaluation which solely adopts the form of formative evaluation rather than its essence (Li, Zheng, Feng, Liu, \& Ma, 2019). Therefore, we shall organize proper training for teachers, learn from each other and exchange experience.

Duifene Teaching Platform has launched such functions as attendance, transcript, teaching evaluation, mutual test between students, questionnaire, forum and classroom questioning, which is consistent with the content of formative evaluation completely, making itself a teaching platform with complementary teaching and evaluation. As the product of "Internet + Information Based Teaching", Duifene Teaching Platform implements evaluation while organizing teaching, so that teaching and evaluation can promote each other. One of the most important means in formative evaluation is the establishment of learning portfolio. Duifene Teaching Platform also functions in statistics and recording of evaluation big data while organizing teaching, which makes formative evaluation speedy and convenient. Duifene Teaching Platform can help optimize the teaching evaluation system, which can track and evaluate every student's learning progress and learning effectiveness, and generate evaluation reports automatically. Such evaluation can provide timely feedback regarding students' learning progress, with which teachers can adjust teaching modes accordingly.

\section{Conclusion}

PAD class provides an idea to solve the problem of teaching quality decline in 
current college classroom, rather than to handle a certain subject. When implemented, we shall adjust it according to the characteristics of different subjects. PAD class focuses on students' learning as a process, and formative evaluation happens to be the evaluation based on the observation and record of students' performance, participation, assignment, enthusiasm, attitude and emotion. An effective mechanism of formative evaluation is the precondition for the smooth implementation of PAD class, which can enable the students used to the traditional teaching mode to get rid of passive learning. Under the guidance of formative evaluation, we can teach students to learn how to take the initiatives in exploring knowledge and improve comprehensive quality by integrating formative evaluation into PAD class, recording their performance in all the steps in the class, contribution to their groups, achievements, etc., commenting on them objectively and impartially, guiding them to take the initiatives in completing the learning tasks effectively, and requiring them to carry out self-assessment and mutual evaluation on the knowledge learned during discussion. When implemented, we shall highlight the integration of formative evaluation into PAD class, instead of imitating its form; what's more important, we shall emphasize the students' dominant position in learning, and stress their improvement of self-learning ability.

\section{Fund Program}

Guangxi higher education undergraduate teaching reform project in $2018+$ "Research and Practice of PAD Classes based on Duifene Platform Combined with Formative Evaluation in Undergraduate Teaching-Taking Analysis and Testing Related Courses of Medical Universities in Ethnic Regions as Examples" + (2018JGA237).

\section{Conflicts of Interest}

The authors declare no conflicts of interest regarding the publication of this paper.

\section{References}

Li, J., Zheng, Y., Feng, W., Liu, H., \& Ma, D. (2019). Formative Evaluation on the Course of Strengthened Instrumental Analysis Based on Moso Tech Class. Health Vocational Education, 37, 41-42.

Sun, J. (2018). Practice and Reflection of Philosophy Course Teaching Based on the Teaching Mode of "PAD Class". Theory and Practice of Contemporary Education, 10, 50-53.

Sun, Y., Hu, Z., Chen, X., Hu, D., \& Li, X. (2020). Discussion on the "Student-Centered" Concept in Large-Class Medical Teaching. Journal of Youjiang Medical University for Nationalities, 42, 252-254+264.

Wang, J., Huang, L., Wu, R., Luo, C., Chen, J., Li, H., Huang, Y., Li, B., Zhao, Q., Fang, X., \& Li, X. (2019). Application of Formative Evaluation in Large-Class Teaching of Human Histology and Embryology in the Context of Internet. Chinese Journal of Anatomy, 42, 418-420. 
Wang, P., Gong, L., Zhu, X., Yang, J., Gao, J., He, J., Lin, A., \& Bu, W. (2020). Practical Exploration of Formative Evaluation Based on Rain Classroom Teaching Mode in Genetics Teaching. Journal of Youjiang Medical University for Nationalities, 42, 385-388+391.

Wu, W., Lin, Q., \& Zhou, Y. (2019). Discussion and Reflection on the Application of Formative Evaluation in Clinical Medicine Teaching. Health Vocational Education, 37, 37-39.

Zhao, W., \& Zhang, X. (2018). PAD Class: A Domestic New Teaching Mode Facilitating In-Depth Learning. Theory and Practice in Education, 38, 47-49. 